\title{
Conflicts of interests and investments
}

"Conflict of interest exists when an author (or the author's institution), reviewer, or editor has financial or personal relationships that inappropriately influence (bias) his or her actions..."

$\mathrm{T}$ he principles and statements of the International Committee of Medical Journal Editors (ICMJE), of which CMAf was a founding member over 25 years ago, guide the editorial policy of this Journal. The ICMJE statement on conflict of interest recognizes that we are all susceptible to bias and, by naming the two main sources of bias in medical journal publications (financial and personal relationships), encourages us to reflect on and disclose possible competing interests. However, under this system most of the self-identified conflicts of interests of authors disclosed to CMAJ editors concerned the nature of authors' personal relationships with colleagues, scientific competitors, students and the like. Disclosures about financial interests were less frequently declared.

Yet, there is increasing evidence that authors with financial relations with the manufacturers of specific products (drugs, devices) are more likely, in their writings and research, to support those products. ${ }^{2}$ In the late 1990s CMA7 revised its rather general conflict of interest policies for articles that mentioned a commercial product by asking the authors specific questions about financial support - travel to meetings, research support, honoraria, investments, royalties and patents. Consistent with the literature, many authors acknowledged that they had received such support but had not declared it since they did not consider that it had inappropriately influenced their decisions. The disclosures are published under the declaration "competing interests" at the end of articles. And in a similar spirit, we have started to undertake to publish regular disclosure statements about potential conflicts of CMAJ editors (www.cmaj.ca/misc/competing_interests_main.shtml).

But is disclosure sufficient? When, if ever, are financial conflicts of interests so great that publication ought to be refused even if they are disclosed? On this matter the ICMJE guidelines are silent, although individual journals are beginning to speak out.

When considering the potential for bias we believe it is helpful to distinguish between types of manuscripts. Original research, which is almost always funded by private com- panies, foundations or governments, has inherently more safeguards against bias (scientific methodology, peer review, ethics review) than narrative reviews and commentaries. Reviews and commentaries are built on selected references and interpretations; the potential for bias in these articles is always present and often difficult to detect.

Several journals have tried to draw the line between acceptable and unacceptable financial conflicts of interest. Attempts

\section{CMAJ's new policy}

Commentaries and narrative reviews or other similar articles, whether commissioned or spontaneously submitted, will not be accepted for consideration for publication if any author has any financial investments (such as equity, shares, derivatives, bonds, but excluding publicly traded mutual funds), receives royalties or similar payments, that in total over the past year have exceeded US\$10 000 per company; or holds a patent (or is likely to or has applied for one or more) in a company that markets a product (or a competitor's product) mentioned in the article. Nor will we accept for publication papers by authors who are employed by such companies, who have a contractual relationship of any type with such companies, or who are named officers or board members of said companies.

by some journals to limit publication of review articles and commentaries to authors who had no financial ties to commercial sponsors largely failed because most researchers working in fields that have commercial potential have ties. Other journals, like The Lancet, have adopted a policy that precludes publication of commentaries and reviews by anyone who "within the past 3 years, and with a relevant company or competitor, has any stocks or shares, equity, a contract of employment, or a named position on a company board; holds ... a relevant patent; or has received ... a fee from any organisation other than The Lancet ... to write, be named on, or to submit [the manuscript]." " The Lancet's policy does not exclude authors who have other financial ties to commercial sponsors: honoraria, speaker fees, travel assistance, consultancies and the like.

The New England Fournal of Medicine has chosen to define significant financial bias that would preclude publication by specifying an upper limit on such financial support (US\$10 000 per company per year). ${ }^{4}$

CMAf's new policy is an amalgam (see text box). It has already helped us with a decision to decline a series of review papers because the author, although an internationally recognized authority in the field, is a major shareholder and co-owner of a company that develops and markets some of the products mentioned in the papers.

There is clearly no absolute threshold above which all biases are detectable. We will continue to modify our conflict of interest policies as we gain experience, listen to reader comments and criticisms, speak with other editors and follow the rapidly expanding research activity in this area. — CMAJ

\section{References}

1. International Committee of Medical Journal Editors (ICMJE). Uniform requirements for manuscripts submitted to biomedical journals: writing and editing for biomedical publication. October 2004. Available: www.icmje.org/\#aboutur (accessed 2004 Oct 29).

2. Stelfox HT, Chua G, O'Rourke K, Detsky AS. Conflict of interest in the debate over calcium-channel antagonists. NEngl 7 Med 1998;338:101-6.

3. James A, Horton R, Collingridge D, McConnell J, Butcher J. The Lancet's policy on conflicts of interest-2004. Lancet 2004;363:2-3.

4. Drazen JM, Curfman GD. Financial associations of authors. $N$ Engl $7 \mathrm{Med}$ 2002;346:1901-2. 